\title{
QUANTITATIVE AND QUALITATIVE ANALYSIS OF DYNAMIC CAVERNOSOGRAPHIES IN ERECTILE DYSFUNCTION DUE TO VENOUS LEAKAGE
}

\author{
CHRISTIAN GEORG STIEF, M.D. \\ ULRICH WETTERAUER, M.D.
}

From the Departments of Urology BWK, Academic Hospital of the

University, Ulm, and the University Clinic, Freisburg, West Germany

\begin{abstract}
Of 521 patients with erectile dysfunction in whom a multidisciplinary approach was used, 145 (27.8\%) showed venous leakage as (concomitant) etiology of the impotence in dynamic cavernosography. The rate of the maintenance flow corresponded well with the response to a standardized intracavernosal injection of vasoactive drugs $(p<0.05)$ in patients with venous leakage. The maintenance flow increased with the age in secondary impotent men. It was not statistically different in patients with or without concomitant arterial insufficiency $(p=0.19)$. Fifty-one of 145 patients $(32.2 \%)$ presented a pathologic cavernosal drainage via a single venous system; $94 / 145$ $(64.8 \%)$ showed a combined venous leakage. The type of leakage corresponded neither to the maintenance flow nor to the response to intracavernosal injections. Our findings show that standardized intracavernosal testing and Doppler have a high predictive value for the status of the venous occlusive system. Exact evaluation of the type of leakage can be made by bidimensional cavernosography only.
\end{abstract}

Recent experimental studies show that the smooth muscle of the cavernous tissue plays a key role in the hemodynamics of penile erection. ${ }^{1.2} \mathrm{~A}$ full rigid erection requires in addition to cavernosal relaxation a strong reduction of the cavernosal outflow. ${ }^{3}$ Hereby two different mechanisms can be differentiated: the passive compression of venous cushions between the cavernosal sinusoids and the tunica albuginea, ${ }^{3}$ and the squeezing of the obliquely running venae perforantes within the tunica albuginea. ${ }^{4}$ So, excessive cavernosal outflow can be caused either by incomplete cavernosal relaxation, e.g., by cavernosal fibrosis due to diabetes, or by disturbances of the squeezing mechanism within the tunica albuginea, or both.

To evaluate the cavernosal outflow in impotent patients, Virag et al. ${ }^{5}$ introduced the dynamic cavernosography, allowing a quantification by the maintenance flow and a qualification by $x$-ray films of the venous leakage.
They proposed that opacification should be done during artificial erection to occlude the physiologically open venous channels and so identify the pathologic drainage. The superficial dorsal veins, draining mainly the glans and the penile skin, empty into the pudendal plexus and/or the saphenous vein(s). They are called ectopic veins if they empty into the saphenous vein(s) (Fig. 1). They communicate with the deep dorsal vein that drains the glans and the corpora cavernosa. The deep dorsal vein empties into the periprostatic plexus and into the internal pudendal veins via some communications (Fig. 2). Furthermore, the cavernosal drainage runs via the cavernous veins merging medially from the crura, and via shunts between the corpora cavernosa and the corpus cavernosum and the glans.

The exact localization of the pathologic drainage is one of the basic requirements for successful venous surgery. Our study presents a 


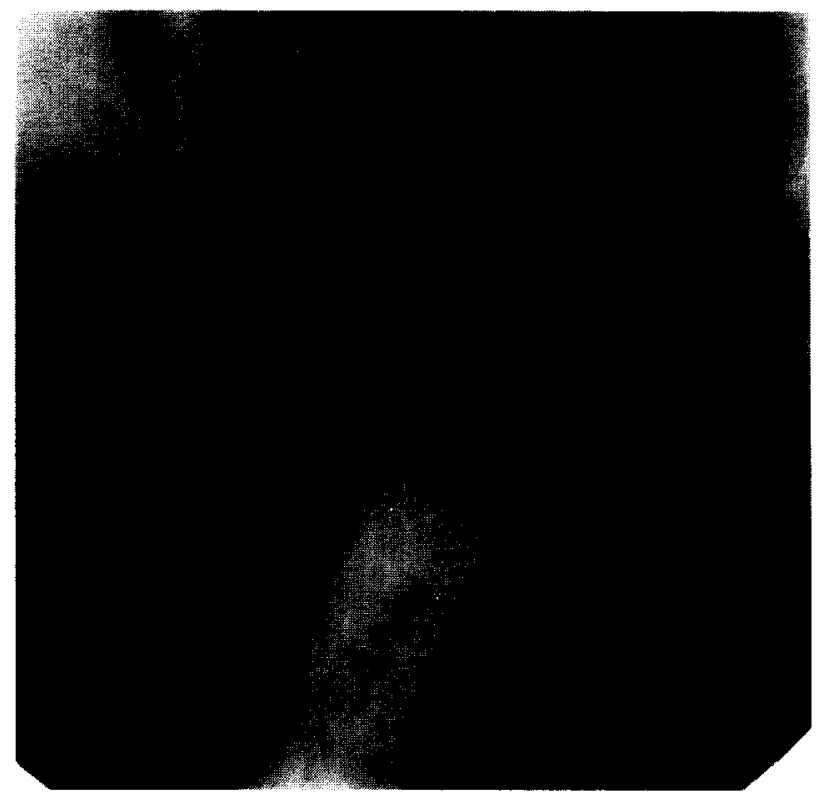

Figure: 1. Abnormal cavernosal drainage in both saphenous veins.

detailed analysis of the different cavernosal drainage systems with correspondent maintenance flows and response to intracavernosal vasoactive drug-testing.

\section{Material and Methods}

Of 521 multidisciplinary approached patients ${ }^{6}$ with erectile dysfunction lasting at least one year, 159 patients underwent dynamic cavernosography: 35 had primary (congenital) erectile impotence and 124 secondary erectile impotence. As an invasive diagnostic study, dynamic cavernosography requires strict indications: (1) an intact penile Doppler after intracavernosal vasoactive drugs and a poor response to vasoactive drugs; (2) no response to high doses of vasoactive drugs; and (3) primary erectile dysfunction. In any patient, cavernosography was considered after extensive noninvasive diagnostic studies including Doppler and standardized intracavernosal injection of a vasoactive drug mixture $(15 \mathrm{mg} / \mathrm{mL}$ papaverine $+0.5 \mathrm{mg} / \mathrm{mL}$ phentolamine). Under hospital conditions, one intracavernosal injection was given per day starting with $0.5 \mathrm{~mL}$ to a maximum of $3 \mathrm{~mL}$ until full erection was induced. Response to this intracavernosal injection was evaluated by a urologist, and the dose needed for an erection lasting a minimum of 15 minutes was tested at least two times to prove reproducibility. ${ }^{6}$

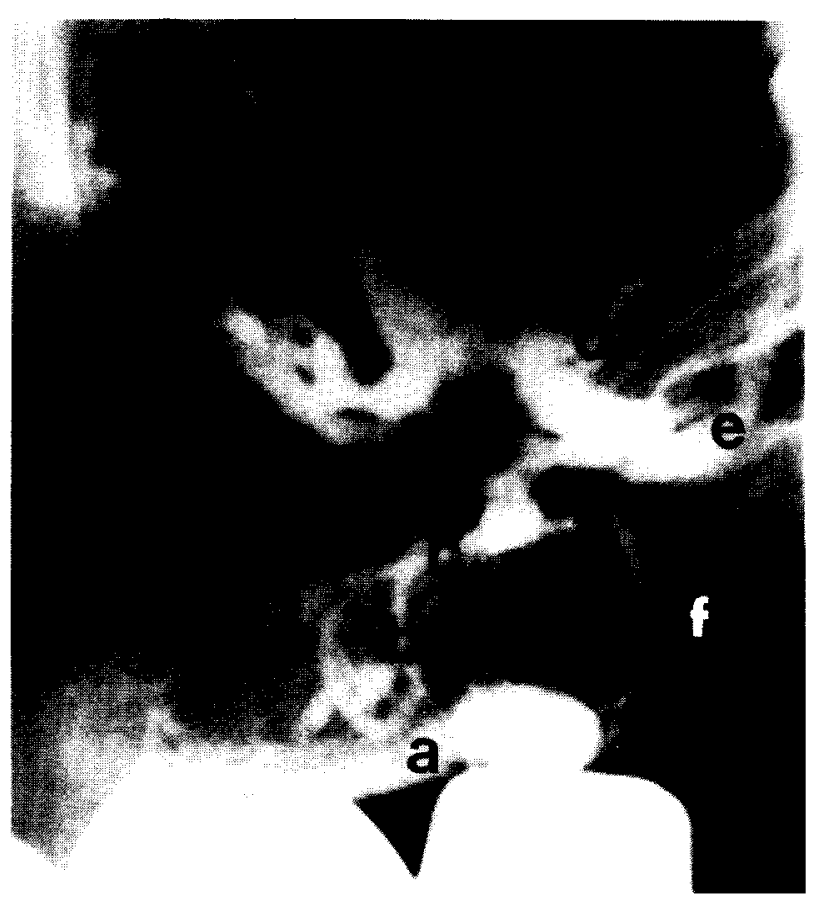

Ficitre 2. To avoid overlaying of drainage of deep dorsal vein by cavernous bodies, spongiosogram is shown. Drainage runs from corpus spongiosum $(a)$ via circumflex veins $(b)$ to deep dorsal vein (c). Deep dorsal vein empties into periprostatic plexus (d) and internal pudendal vein (e). Additional spongiosal drainage via ectopic vein $(f)$.

Under sterile conditions, the proximal left $\mathrm{c}$. cavernosum was punctured with a 19-G needle and connected to a perfusion pump. The proximal right $c$. cavernosum was punctured with a 26-G needle and connected to a Strattham transducer for pressure recording. Then the penis was perfused with saline (at $37^{\circ} \mathrm{C}$ ) at a rate of $300 \mathrm{~mL} / \mathrm{min}$. As soon as full rigidity was reached (corresponding intracavernosal pressure $>80 \mathrm{~mm} \mathrm{Hg}$ ), the minimum flow to maintain full erection was measured (maintenance flow). The penis was maintained in artificial erection by undiluted non-ionic contrast medium perfusion. For exact localization of the venous draining system, $x$-ray films were taken in anteroposterior (ap) and in oblique $\left(30^{\circ}\right)$ positions.

If full rigidity could not be achieved within ninety seconds (corresponding to $450 \mathrm{~mL}$ saline), measurement of the maintenance flow was abandoned to prevent circulatory side effects, and opacification was done in semirigid state.

After the opacification the penis was perfused with 30 to $50 \mathrm{~mL}$ of saline to wash out the 


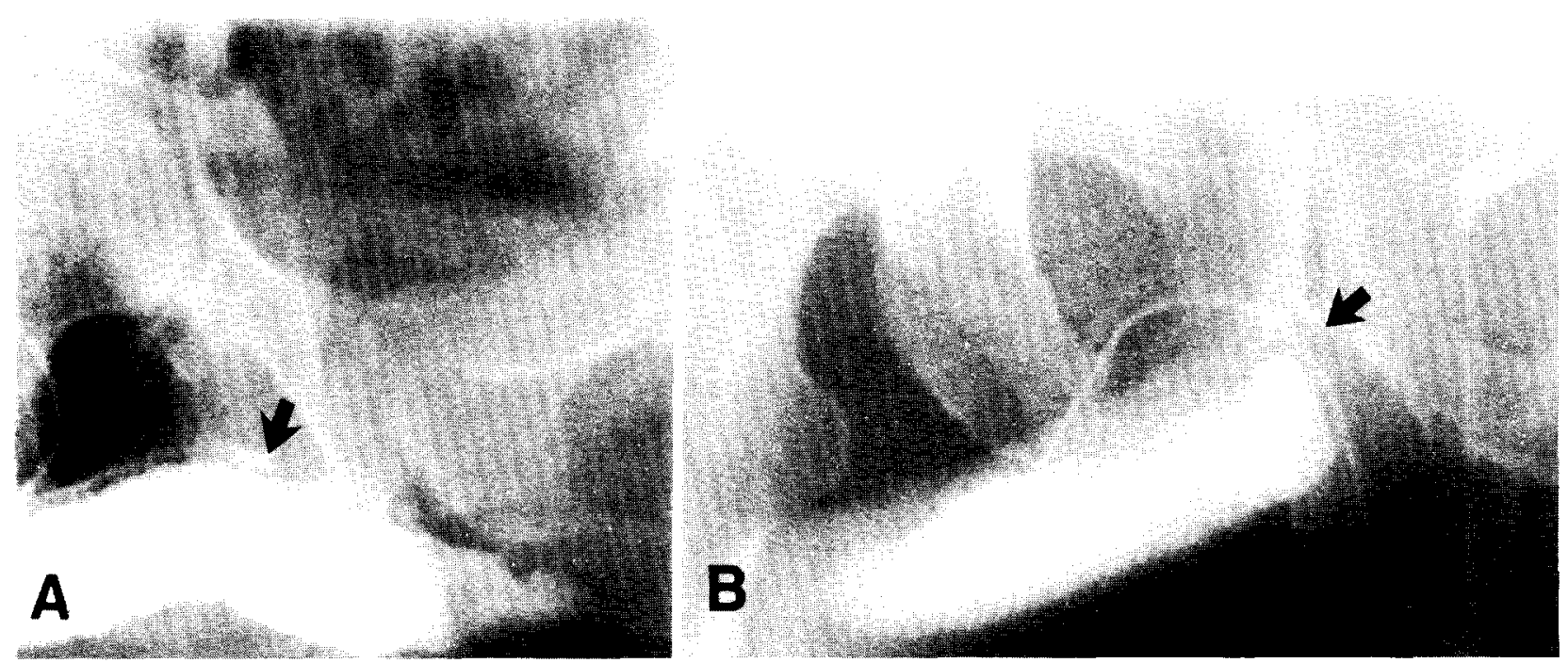

Figure 3. Cavernosography of normal potent man. Beside slight opacification of deep dorsal vein $(\rightarrow)$ no cavernosal drainage is seen in artificial erection. (A) Anteroposterior and (B) oblique views.

hyperoncotic contrast medium because of possible endothelial alterations of the sinusoids. The needles were removed, and the puncture sites were compressed manually at least five minutes to prevent hematomas.

\section{Results}

As control group, 14 young potent men with congenital penile curvature underwent dynamic cavernosography. The maintenance flow was 18 to $65 \mathrm{~mL} / \mathrm{min}$ (mean $41 \mathrm{~mL} / \mathrm{min}$ ). Except for the opacification of the decp dorsal vein, no cavernosal drainage was seen (Fig. 3A, B).

One hundred thirteen of 124 patients $(91 \%)$ with secondary impotence and 32 of 35 patients $(91 \%)$ with primary impotence showed a maintenance flow exceeding $70 \mathrm{~mL} / \mathrm{min}$ and an abnormal cavernosal drainage in the x-ray films (venous leakage). The maintenance flow increased with age, but these findings were statistically significant $(p<0.05)$ only when comparing patients with secondary impotence in the fourth decade to patients over fifty years of age. The same data were found when comparing patients in the fifth decade to those over sixty years of age (Table I).

In about one third of the patients showing venous leakage, a single abnormal drainage system was found, the remaining presenting a combination of different systems. The most frequent pathologic drainage runs via the deep dorsal vein as seen in 27.4 percent of patients with secondary impotence and in 15.6 percent with primary impotence. The combination of deep dorsal and cavernosal veins was found in 24.8 percent and 25 percent, respectively (Fig. 4A) and deep dorsal and ectopic veins in 18.6 percent and 18.7 percent, respectively (Table IIA). There were no significant differences between the maintenance flows corresponding to the type of pathologic drainages except to the drainage via ectopic veins $(p<0.01)$. There

TABLE 1. Maintenance flow according to age

\begin{tabular}{crcrc}
\hline Age & $\mathrm{n}$ & $\begin{array}{c}\text { Primary Impotence } \\
\text { Maintenance-Flow } \\
\mathrm{mL} / \mathrm{min}+\text { SEM }\end{array}$ & $\begin{array}{c}\text { Secondary Impotence } \\
\mathrm{n}\end{array}$ & $\begin{array}{c}\text { Maintenance-Flow } \\
\mathrm{mL} / \mathrm{min}+\text { SEM }\end{array}$ \\
\hline-30 & 21 & $197.0 \pm 23.4$ & 4 & $285.0 \pm 40.9$ \\
-40 & 8 & $203.7 \pm 36.7$ & 16 & $162.2 \pm 26.2$ \\
-50 & 3 & $273.3 \pm 76.7$ & 36 & $215.1 \pm 17.4$ \\
-60 & $\ldots$ & 26 & $265.9 \pm 18.7$ \\
$60+$ &. & 31 & $276.0 \pm 16.1$ \\
\hline
\end{tabular}

TABLE II. Abnormal cavernosal draining systems

\begin{tabular}{|c|c|c|c|c|c|}
\hline \multirow[b]{2}{*}{ Type of Drainage } & \multicolumn{3}{|c|}{$\begin{array}{l}\text { Primary } \\
\text { Impotence }\end{array}$} & \multicolumn{2}{|c|}{$\begin{array}{l}\text { Secondary } \\
\text {-Impotence }\end{array}$} \\
\hline & $\mathrm{n}$ & $\%$ & $\mathrm{n}$ & $\%$ & $\begin{array}{l}\text { Maintenance- } \\
\text { Flow + SEM }\end{array}$ \\
\hline A. IndIVIDUAL FINDINo & & & & & \\
\hline $\mathrm{ddv}$ & 5 & 15.6 & 31 & 27.4 & $241.5 \pm 15.9$ \\
\hline $\mathrm{ddv}+\mathrm{ev}$ & 6 & 18.7 & 21 & 18.6 & $234.9 \pm 19.2$ \\
\hline ev & 6 & 18.7 & 6 & 5.3 & $100.5 \pm 16.7$ \\
\hline $\mathrm{ddv}+\mathrm{cv}$ & 8 & 25.0 & 28 & 24.8 & $273.7 \pm 23.9$ \\
\hline $\mathrm{ddv}+\mathrm{cv}+\mathrm{ev}$ & 1 & 3.2 & 16 & 14.2 & $260.1 \pm 32.6$ \\
\hline $\mathrm{ddv}+\mathrm{cgs}+\mathrm{ev}$ & 4 & 12.5 & 5 & 4.4 & $186.7 \pm 8.8$ \\
\hline $\mathrm{dd} v+\mathrm{cv}+\mathrm{cgs}+\mathrm{ev}$ & 2 & 6.3 & 3 & 2.6 & . \\
\hline $\mathrm{cv}$ & . & . & 2 & 1.8 & . \\
\hline ptf & . & . & 1 & 0.9 & . \\
\hline $\begin{array}{l}\text { Ovfraill Occurrenct: } \\
\text { ddy }\end{array}$ & 26 & 81.3 & 104 & 92.0 & \\
\hline $\mathrm{ev}$ & 19 & 59.4 & 51 & 45.1 & \\
\hline $\mathrm{cv}$ & 11 & 34.4 & 49 & 43.3 & . \\
\hline cgs & 6 & 18.8 & 8 & 7.0 & . \\
\hline
\end{tabular}



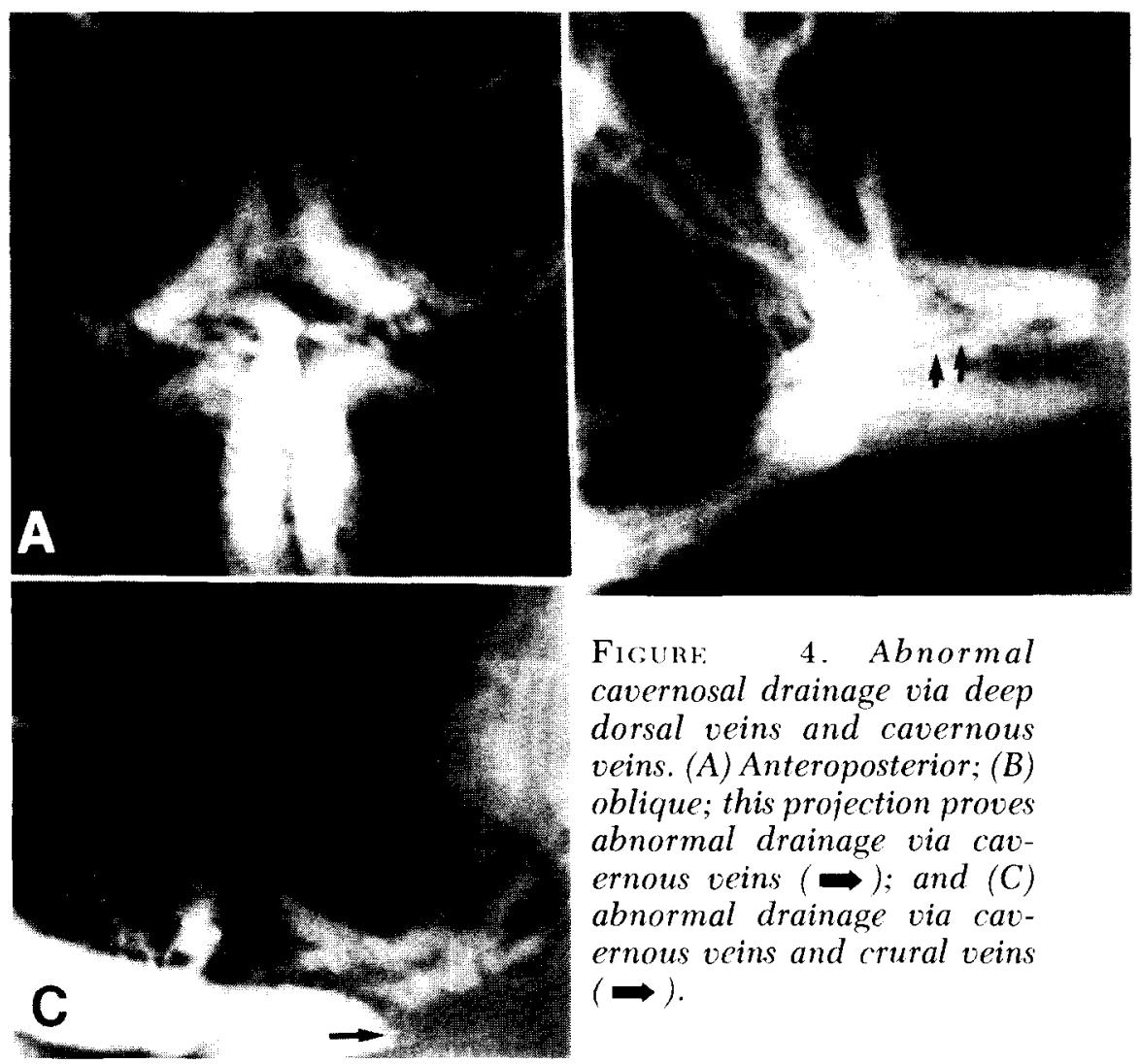

Ficure 4. Abnormal cavernosal drainage via deep dorsal veins and cavernous veins. (A) Anteroposterior; (B) oblique; this projection proves abnormal drainage via cavernous veins $(\rightarrow)$; and $(C)$ abnormal drainage via cavernous veins and crural veins $(\Rightarrow)$

was also no significant difference between the pharmacotesting results related to the different types of drainage.

The deep dorsal vein(s) was part of the anomalous drainage in 81.3 percent of patients with primary impotence and in 92 percent of patients with secondary impotence. The ectopic vein(s) was seen in 59.4 percent and 45.1 percent, respectively, the cavernous vein(s) in 34.4 percent and 43.3 percent, and a cavernosoglandular shunt (Fig. 5) was found in 18.8 percent and 7.0 percent (Table IIB). In 28 percent of the patients with cavernous veins crural veins could be seen additionally (Fig. 4B).

There was a significant correlation between the maintenance flow and the intracavernosal injection. Up to a flow of $60 \mathrm{~mL} / \mathrm{min}$ (no venous leakage), the mean dose of the papaverine and phentolamine mixture to induce a full erection was $0.37 \mathrm{~mL}$, whereas patients with a flow up to $150 \mathrm{~mL} / \mathrm{min}$ (moderate leakage) needed a mean of $1.17 \mathrm{~mL}(\mathrm{p}=0.04)$. Patients with a maintenance flow of up to $300 \mathrm{~mL} / \mathrm{min}$ (severe leakage) needed a mean of $1.81 \mathrm{~mL}$ to achieve full tumescence or semirigid erection (versus $<60 \mathrm{~mL} / \mathrm{min}, \mathrm{p}=0.001)$. Only $2 / 45$ patients of this group could reach full erection after the intracavernosal injection (Table III).

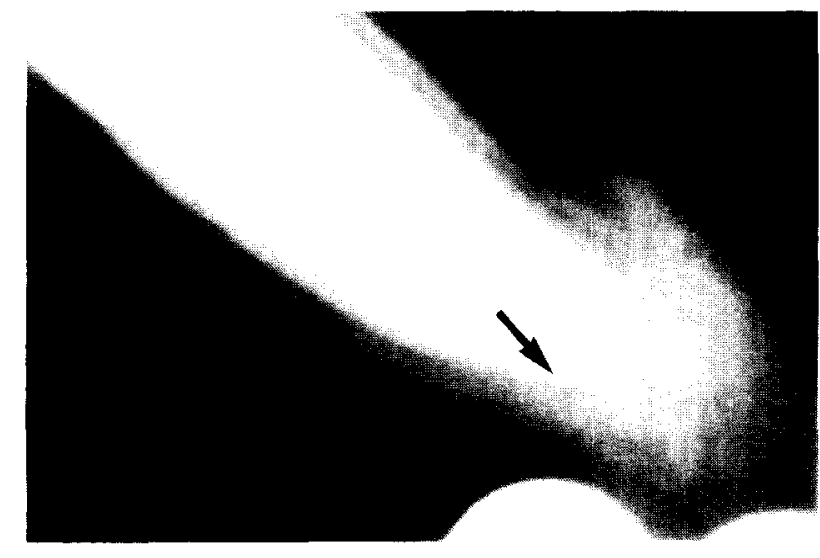

Figure 5. Corporoglandular fistula $(\rightarrow)$ with opacification of glans.

TABIE III. Correlation between rate of maintenance flow in secondary impotence patients $(n=124)$ and response to standardized intracavernosal injection of vasoactive drugs

\begin{tabular}{|c|c|c|c|c|}
\hline $\begin{array}{c}\text { Maintenance } \\
\text { Flow } \\
\text { (mL/min) }\end{array}$ & $\begin{array}{c}\text { No Reaction } \\
\text { or Slight } \\
\text { Tumesc. to } \\
3 \mathrm{~mL} \text { (n) }\end{array}$ & $\begin{array}{c}\text { Full Tumesc: } \\
\text { or Semirigid } \\
\text { Erection } \\
n \mathrm{~mL}+\mathrm{SEM}\end{array}$ & & $\begin{array}{l}\text { Full } \\
\text { Erection } \\
\text { mL }+ \text { SEM }\end{array}$ \\
\hline-60 & & 2 & 11) & $0.37 \pm 0.05$ \\
\hline-150 & 1 & $16 \quad 1.53 \pm 0.15$ & 17 & $1.17 \pm 0.16$ \\
\hline-300 & 10 & $21 \quad 1.81 \pm 0.19$ & 3 & 1.75 \\
\hline wer 300 & 25 & $182.12 \pm 0.17$ & 2 & 2.5 \\
\hline
\end{tabular}


Fifty three of 143 patients ( $37 \%$ ) with venous leakage had arterial insufficiency as evaluated by Doppler after papaverine, which means severely reduced flow or no flow in both cavernous arteries. The maintenance flow in the group without arterial insufficiency was $205 \pm$ $14 \mathrm{~mL} / \mathrm{min}$ compared with $235 \pm 17 \mathrm{~mL} / \mathrm{min}$ in the group with arterial insufficiency. This difference was not statistically significant $(p=$ $0.19)$.

Ecchymosis $(<5 \mathrm{~mm})$ occurred in 27 percent of the patients, mainly at the site of the 19-G needle. We saw three important subcutaneous edemas of the penile shaft: Two occurred during saline perfusion by displacement of the needle out of the corpora. They rapidly resorbed without any further treatment. One occurred during contrast medium perfusion and was followed by continuous penile shaft swelling caused by the hyperoncotic contrast medium. It resorbed without further therapy within two days.

\section{Comment}

Besides measuring the maintenance flow, Virag et al..$^{5}$ also measured the flow needed to induce an erection. Because this induction flow depends mainly on the size of the penis and the cavernosal drainage (measured by the maintenance flow), we think that the maintenance flow is the appropriate quantification of the venous leakage. The maintenance flow of our control group corresponds to those described by others. ${ }^{5.7 .8}$ We did not include patients with Peyronie disease reporting normal rigidity and tumescence because the venous occlusive system may be affected, with an increased inflow compensating a moderate venous leakage.

Our findings show an increase of the maintenance flow in secondary impotence with the age, starting with the fourth decade. This could reflect a progressing degeneration of the cavernous tissue, accelerated by risk factors such as smoking, diabetes, or hypertension that are found in most of the patients with secondary impotence. ${ }^{9}$ The younger patients in this group are post-traumatic or postradiation impotent males where mechanisms other than continuous cavernosal degeneration are to be searched for. Post-traumatic venous fistula or radiation-induced fibrosis were found in those patients.

Recently, various authors reported successful surgery for erectile dysfunction due to different types of venous leakages. ${ }^{10}{ }^{14}$ Although one of the basic requirements for successful penile ve- nous surgery is the precise identification of the leaking system, little attention was given to this fact. ${ }^{8,15}$ According to our findings, the anteroposterior documentation of the cavernosal drainage is not sufficient to detect the different venous systems in all cases, especially the cavernous veins. Proper identification of the pathologic draining system requires additional oblique $\mathrm{x}$-ray films.

The good correlation between the response to a standarized intracavernosal injection of vasoactive drugs and the rate of the abnormal outflow is in agreement with the findings of other authors. ${ }^{8}$ This explains our high rate $(91 \%)$ of venous leakages found by cavernosometry in the patients where leakage was suspected by less invasive studies. Penile Doppler done after injection of vasoactive drugs and a standardized testing with intracavernous injection of papaverine and phentholamine has a high predictive value for the status of the venous occlusive system (Table III). Besides appropriate cavernosal relaxation and venous occlusion, a full erection requires an adequate arterial supply.1.1 this arterial supply is not altered, e.g., by arteriosclerosis, it can compensate a moderate venous leakage by increasing the arterial inflow. Therefore, the arterial supply (measured by Doppler) and the cavernosal relaxation (measured by standardized intracavernosal injection of vasoactive drugs) both have to be taken into account for the consideration of the venous occlusive system. A differentiation of the type of leakage was not possible by the pharmacotesting or by the maintenance flow alone.

In the animal model, acute or subacute penile arterial occlusion produced insufficiency of the venous occlusive mechanisms. ${ }^{16}$ There was no significant difference between the maintenance flow in our patients with and without concomitant arterial insufficiency. Further studies are necessary to conclude a possible relationship between arterial and venous etiology.

We conclude that dynamic cavernosography is a valuable functional evaluation for quantification and qualification of the cavernosal drainage. Postoperative results will have to prove if the theoretical advantage of the pharmacocavernosography ${ }^{15}$ leads to better therapeutic results by imitating a more physiologic erection.

Medizinische Hochschule Konstanty-Gutschowstr. 8 D-3000 Hannover G1, F.R.G.

(DR. STIEF) 


\section{References}

1. Lue TF, et al: Hemodynamics of canine corpora cavernosa during erection, Urology 24: 347 (1984).

2. Juenemann KP, Lue TF, Fournier GR, and Tanagho EA: Hemodynamics of papaverine- and phentolamine-induced erections, J Urol 136: 158 (1986).

3. Fournier GR. Juenemann KP, Lue TF, and Tanagho EA Mechanisms of venous occlusion during canine penile erection. J Urol 137: 163 (1987).

4. Lierse W: Blood vessels and nerves of the human penis, Urol Int $37: 145$ (1982)

5. Virag R, Legman M, Zwang G, and Dermange H: Lutilisation de l'erection passive dans l'exploration de l'impuissance d'origine vasculaire, Contracep Fertil Sexu 7: 707 (1978).

6. Stief CG, Baehren W, Gall H, and Scherb W: Functional evaluation of penile hemodynamics, J Urol 139: 734 (1988).

7. Wespes $\mathbf{E}$, and Schulman CC: Parameters of erection, $\mathrm{Br} \mathrm{J}$ Urol 56: 416 (1984).

8. Porst $\mathrm{H}$, Ahlen $\mathrm{H}$, and Vahlensiek $\mathrm{W}$ : Relevance of dynamic cavernosography to the diagnosis of venous incompetence in erectile dysfunction, J Urol 137: 1163 (1987).

9. Virag R: A new field in angiology, Inter Angio 3: 217 (1984).

10. Ebbehoj J, and Wagner G: Insufficient penile erection due to abnormal drainage of cavernous bodies. Urology 13: 507 (1979).

11. Wespes E, and Schulman CC: Surgical treatment of a curable cause of impotence, J Urol 133: 796 (1985).

12. Lewis RL, Puyau FA, and Bell DP: Another surgical approach for vasculogenic impotence, J Urol 136: 1210 (1986).

13. Gilbert $P$, and Stief CG: Spongiosolysis for distal venous leakage, J Urol 138: 784 (1987).

14. Stief CG, Gall H, Scherb W, and Baehren W: Erectile dysfunction due to an ectopic penile vein, Urology (in press).

15. Lue TF, Hricak K, Schmidt RA, and Tanagho EA: Functional evaluation of penile veins by cavernosography in papaverine-induced erection, J Urol 135: 479 (1986).

16. Bookstein JJ, Machado T, and Rippon D: Production of penile venoocclusive insufficiency by arterial occlusion in a canine model, J Urol 137: 1283 (1987). 